dual): organiza las competencias que debe activar el individuo para conectar un problema del mundo real con las matemáticas que tiene que poner en juego para intentar su resolución.

En este sentido, la aportación que el profesor Nortes Checa y su equipo hacen en esta magnífica obra se nos presenta como una inestimable ayuda para los profesores de Matemáticas. Podríamos decir, como indica el título, que se trata de una recopilación exhaustiva de actividades prácticas para llevar al aula, pero es mucho más que eso: todas las tareas propuestas conectan con las tres dimensiones comentadas anteriormente, y ello hace que la obra posea una fundamentación y una estructuración impecables.

Así, podemos encontrarnos a modo de ejemplo con una sesión dedicada a la interpretación y elaboración de croquis, planos y mapas. En ella se nos muestra la dimensión matemática, con los distintos conceptos matemáticos implicados en las actividades que aparecerán más adelante, pero complementada además esa dimensión con una serie de aspectos históricos que ayudan a una más adecuada contextualización; se nos presentan las actividades propiamente dichas, incardinadas en una serie de ricas situaciones que hacen que el alumnado no pueda evitar implicarse en ellas; y se nos manifiestan también los aspectos didácticos a tener en cuenta a la hora de llevar a cabo las propuestas concretas de aula, aspectos que articulan y dotan de sentido a todo el proyecto de trabajo.
Y esta estructura unificadora se repite en todos los capítulos del libro, como también aparece en todos ellos un apunte a los correspondientes recursos TIC de interés, como no podía ser menos, máxime en esta época, que las TIC posiblemente estén haciendo que sea la más estimulante intelectualmente de la Historia.

Un apartado importante lo constituye la gran cantidad de materiales didácticos que presenta, cada uno de ellos con su debida fundamentación respecto a las tres dimensiones mencionadas, y con apuntes claros y precisos acerca de los objetivos didácticos plausibles alcanzables con cada uno de ellos, así como con las correspondientes actividades de aula.

Es de agradecer la iniciativa del profesor Nortes Checa y su equipo, y deducimos del título que tienen previsto editar un segundo libro. Si es así, esperamos tener pronto la oportunidad de contar con él, pues con ello se nos hará más sencilla la materialización del que pensamos es el gran objetivo de la Educación en clave de competencias: "priorizar los contextos para dar sentido a los contenidos: partir de la vida para educar para la vida" (Claudi Mans).

Recensor: Eduardo Manuel Zurbano Fernández Universidad de Oviedo (España)

\title{
Cosmopolitismo y Educación. Aprender y trabajar en un mundo sin fronteras
}

\author{
Miguel Ángel Santos Rego (Ed.) (2013). \\ Valencia (España): Brief Ediciones, 221 pp.
}

Hace unos años, en referencia a una obra colectiva sobre "complejidad y educación" ahormada por el mismo editor de las páginas que ahora nos ocupan, escribía que "nuestro tiempo ya del siglo xxi se ha hecho tan plural, intrincado, enredado, antinómico, vario, multiforme, incierto, azaroso, impredecible y cambiante en todos los ámbitos y niveles que queramos y podamos imaginar, y que ni siquiera imaginar podamos, que más que nunca se hace necesario pararnos un momento a meditar y a reflexionar con calma en nuestra relación con él, en nuestro inevitable maridaje"; y añadía entonces: "y en este intrincado pensamiento, de manera forzosa e ineludible, ¡cómo no!, han de situarse siempre también la dimensión y la perspectiva pedagógicas, la educación como proceso complejo y multiforme que ya es, la posibilidad de que pueda haber y de que haya otros modos de entender y de concebir la racionalidad de la acción educativa y su propia y entrañada complejidad".

Al releer ahora aquella reseña, creo que estas palabras se pueden acomodar perfectamente al presente libro por razones varias, pero fundamentalmente por dos: porque, al igual que aquella obra colectiva, ésta, colectiva también, nos mueve, asimismo, a la reflexión sobre el hecho educativo en el mundo en que nos ha tocado vivir y porque esa reflexión nos proyecta ahora hacia el cosmopolitismo como un "modo de entender y concebir la racionalidad de la acción educativa y su propia y entrañada complejidad". Como bien escribe el profesor Santos Rego en la presentación del libro, éste «es el resultado de una invitación a pensar y a compartir ideas, pero también cursos de acción en torno a la agenda educativa de un tiempo que, con sus complejidades e incertidumbres, parece alertarnos sobre la necesidad de confluencias efectivas en la forma de entender el aprendizaje y el conocimiento, más allá de las singularidades cultu- rales pero sin perder de vista lo más genuino de la diversidad, que es, justamente, aquello que otorga valor a una perspectiva cosmopolita merecedora de atención y exploración por cuanto las mejores ansias de los seres humanos seguirán apuntando a la paz y al progreso».

Como obra colectiva que es, la mirada que se ofrece es diversa, multiplicada, caleidoscópica, plural, de matices varios y de ángulos distintos, pero complementarios, que, desde las diferentes atalayas, van descubriendo y desgranando teselas de pensamiento para construir un atractivo mosaico en torno al tema que se aborda: cosmopolitismo y educación; un binomio sin duda necesario en nuestro tiempo y en nuestra sociedad extensa y sin fronteras por cuanto, más allá incluso de otras múltiples consideraciones que podrían hacerse, se ha de ir asentando y maridando cada vez más estrechamente por el propio cumplimiento de la historia que fluye -ahora a menudo también con múltiples y variadas intrahistorias que podemos conocer como en ningún otro momento- y por la propia inercia de los tiempos. No olvidemos, por ejemplo, cómo el flujo migratorio universal -como cruce e interacción de seres humanos, culturas, lenguas, religiones...- no es ya un fenómeno meramente coyuntural, sino un componente estructural, incardinado indefectiblemente en el ser y en el estar de nuestro tiempo y de nuestra sociedad compleja y plural, que nos ha de conducir cada vez más y en mayor medida hacia un interculturalismo que pueda ser enriquecedor y provechoso para la sociedad y para cada uno de sus individuos.

La obra, con la colaboración de profesores de diversas universidades españolas y norteamericanas, se estructura en dos partes. La primera, de impronta más general, acoge cinco trabajos bajo el título de "Cosmopolitismo y Educación para una conciencia global". En ella se encuentran aquellos estudios que buscan presentar una mirada 
más amplia o alientan algunos de los principios que deberían guiar la educación cosmopolita de este aún nuevo siglo. En la segunda, predomina una dimensión más próxima e inmediata. Recoge, así, siete trabajos presentados conjuntamente como "Aprendizaje, formación y trabajo en un mundo sin fronteras".

Abre la obra el profesor Juan Escámez centrando el tema en un motivo que, de uno u otro modo, va a ser recurrente en gran parte de las páginas del libro: los valores éticos y la educación en valores como marchamo necesario y de exigencia ineludible para hacer a los ciudadanos cosmopolitas y asentar la propia dignidad humana. Vicent Gonzálvez y Rafaela García mueven su reflexión hacia el cosmopolitismo cívico y los fines de una educación para el desarrollo y la cooperación que busque lograr un ciudadano educado en las libertades y en los principios universales dirigidos siempre a promover el bien de todos. José Luis Álvarez y Hugo González se adentran en la educación interreligiosa como componente esencial de una educación intercultural para la convivencia y la interacción entre diversos en una sociedad cosmopolita. La seguridad humana, la educación y la paz para un mundo global constituyen el triángulo que sirve a la reflexión y a las propuestas de Concepción Naval y de Eugenia López-Jacoiste. La primera parte de la obra se cierra con unas páginas en las que Merry M. Merryfield aborda y "repiensa" una educación global a través del cosmopolitismo que lleve a superar el etnocentrismo y a lograr una perspectiva más universal, más abierta y, por ende, también más enriquecedora para el propio ser humano.

La segunda parte se inicia con la palabra del académico de la RAE Darío Villanueva, que la usa cabalmente para, con la suya, considerar la palabra de hoy y sus nuevos modos y moldes en esta nueva era tecnológica y cibernética, en especial en lo que atañe a la palabra literaria. Joaquín García Carrasco, entre otras cuestiones, se apoya en lo cultural e identitario en su planteamiento del proceso formativo para la construcción del ideal cosmopolita. Por su parte, Miguel Ángel Escotet dirige su mirada a la Universidad y a los aprendizajes y conocimiento necesarios y pertinentes en este nuevo contexto. Mar Lorenzo desciende al mundo del trabajo, la formación para el empleo, el empleo mismo, la cualificación y la inserción laboral en unos momentos en los que, especialmente en nuestro país, la crisis obliga a prestar singular atención a este ámbito de tanto calado social y de tanto drama personal. Carmen Palmero y Alfredo Jiménez ahondan, por su parte, en la educación permanente, en el aprendizaje a lo largo de toda la vida que impone este tiempo y que se plantea desde todas las instancias políticas y educativas. Miguel Ángel Santos, ante la necesidad inexcusable de una educación para una sociedad cosmopolita, señala otra necesidad, también ineludible: la de una nueva, adecuada y pertinente formación del profesorado. Cierra la obra Sonia Nieto atendiendo también al profesorado y su formación ante esta nueva realidad en la que la consideración de lo global, de los crecientes flujos migratorios y de las mayores desigualdades sociales ha de guiar, si queremos que sea provechosa, la nueva senda de la educación de nuestros jóvenes.

Cosmopolitismo y Educación. Aprender y trabajar en un mundo sin fronteras es, en suma, una obra varia y de acendrado interés que brinda a los profesores de cualquier nivel y a todas las personas preocupadas por el hecho educativo la posibilidad de reflexionar sobre la educación de nuestros días, sobre su devenir y sobre la propia tarea docente en un mundo de claroscuros como éste que nos ha tocado vivir y en un siglo que despierta tantas y tantas expectativas y, a la vez, tantas y tan grandes incertidumbres.
Recensor:

Jesús Hernández García Universidad de Oviedo (España) 